\title{
Strengthening Social Skills in Students With an Intellectual Disability in Secondary Education
}

\author{
Drossinou-Korea Maria, Panopoulos Nikolaos \\ University of Peloponnese, Greece
}

\begin{abstract}
During recent decades, one of education's most important issues is the idea of inclusion regarding the students' full participation to the mutual school environment. In addition, in the international scientific bibliography, it is stated that children with Intellectual Disability (ID) can integrate socially at school. However, the social benefits of inclusive education cannot always be reached. Studies have shown that just putting students with ID in a common school is not always adequate, as their social abilities are insufficient and because of that interventions are required. In this paper, we will examine school inclusion of students with ID having in mind that it is connected firstly to the modification of educational techniques using a Targeted, Individual, Structured, Integrated Program for Students with Special Educational Needs (TISIPfSENs). We will focus to the enhancement of their social skills facing school as one of their educational areas inside the community. The results showed that educational interventions that are focused on the enforcement of social skills are a basic priority for the inclusion of students with ID inside the school community.
\end{abstract}

Keywords: intellectual disability, social skills, TISIPfSENs

\section{Introduction}

During recent decades, one of education's most important issues is the idea of inclusion regarding the students' full participation to the mutual school environment (Ainscow, Dyson, \& Weiner, 2013). Inclusion refers to the constant efforts of overcoming any social discrimination to students, such as that to students with special educational needs (SEN), and more specifically, it focuses on the educational choices and teaching methods that aim at the lifting of any obstacles concerning the participation of these students to any learning activities. Inclusion is highly supported by those who believe that the lack of inclusive techniques does not agree with the educational equality, a fact that led many countries to change their educational tactics by placing students with special educational needs like those with intellectual disability (ID) in the same classrooms with students without SEN (Avissar, Licht, \& Vogel, 2016; Strogilos \& Tragoulia, 2013; Cornelius \& Balakrishnan, 2012).

The educational inclusion of students with ID depends on circumferences which determine it directly. So the researchers focus on the development of inclusive procedures such as modifying the educational system by checking the beliefs of the teachers on what concerns its application (Nitzan \& Roth, 2014; Avramidis \&

Drossinou-Korea Maria, assistant professor of special education and training, Doctor of Psychology, Faculty of Humanities and Cultural Studies, Department of Philology, University of Peloponnese, Greece.

Panopoulos Nikolaos, Ph.D., student, Faculty of Humanities and Cultural Studies, Department of Philology, Schools of Secondrary Education, Peloponnese, Greece. 
Norwich, 2002; McNally, Cole, \& Waugh, 2001), the behavior of the typical students towards their classmates with SEN (Soulis et al., 2016), the schools' development, the evolution of the educational system, the systemic model, and the educational methods in the classroom inspired by Kurt Lewins' saying that "we can't understand an organism until we try to change it" (Ainscow, Booth, \& Dyson, 2006, p. 13).

In addition, in the international scientific bibliography, it is stated that children with SEN such as those with ID can integrate socially at school by communicating with their typical classmates and because of that the United Nations (UN) convention suggests the social co-existence of students with ID in the general class (United Station, 2006). Early interaction between students with ID and their classmates contributes to the growth of their adaptive and social skills (Brooks, Floyd, Robins, \& Chan, 2015). Furthermore, interactions between students with ID and their classmates in high school seem to be of great importance. The nature and the decree of the relationship between students with ID and their peers during adolescence may affect their self-esteem, their spiritual growth, their academic performance, and their behavior (Cutts \& Sigafoos, 2001). However, the social benefits of inclusive education cannot always be reached. Studies have shown that just putting students with ID in a common school is not always adequate, as their social abilities are insufficient and because of that interventions are required (Schwab, Gebhardt, Krammer, \& Gasteiger-Klicpera, 2015; Avramidis, 2013).

In this paper, we will examine school inclusion of students with ID having in mind that it is connected firstly to the modification of educational techniques using a Targeted, Individual, Structured, Integrated Program for Students with Special Educational Needs (TISIPfSENs) (Drossinou-Korea, 2017; Drossinou-Korea \& Panopoulos, 2017). We will focus to the enhancement of their social skills facing school as one of their educational areas inside the community.

\section{Social Skills}

The lack of social skills is a criterion to define people with ID as mentally damaged. In many definitions, concerning the nature of ID is clearly stated that supporting these people grow their social skills is mandatory. The Diagnostic and Statistical Manual of Mental Disorders, DSM 5, stated that it is about a mental deficit accompanied with a lack concerning the adaptive function. It then mentioned the criteria required for the diagnosis of the mental growth disorder. One of them is the defective operation of the general mental abilities compared with the age and the persons' social group in their everyday activities (communication, social participation, general functionality at school or at work, personal independence at home, and their social environment) (American Psychiatric Association, 2013). The International Statistical Classification of Diseases and Related Health Problems (ICD-10) referred to mental dysfunction as a state of delayed or poor development of the mind. It is described by a disorder in the skills that emerge during the growth period and contributes to the level of intelligence including cognitive and social skills (World Health Organization, 2014). Amongst others, it refers to the adaptive behavior of the people with ID as disturbed. The last ability refers to the difficulties of the students with ID to adjust because they have not developed their social skills in their natural and social environment. Students with ID face educational challenges such as achievements and abilities of their adjusting capability. These challenges include difficulties in focusing or maintaining attention to tasks, memory disorders and in many other academic fields such as the generalization of taught knowledge to new areas and language improvement. Except learning challenges ID is related with challenges in social skills and the preservation of the appropriate behavior (Bouck \& Park, 2016). 
According to Garrote (2017), there is not a clear definition for social skills, however it is commonly accepted that social skills are connected to successful social interactions and to making healthy social relationships. Socially adequate persons use their social interactions to reach their goals and their needs when at the same time they have in mind the needs and goals of others. So, there is a clear distinction between these social skills that are important for oneself and those that are important for others. However, students with ID have difficulties with self-oriented social skills such as commencing social interactions and with skills oriented to others such as cooperation and positive social behavior.

The view that children gain a large amount of social behaviors and skills by socially interacting with their peers led students with ID to general schools in Greece through the institution of parallel support (Strogilos \& Tragoulia, 2013; Vlachou, 2006). These way efforts are made to have an essential inclusive education, by using theories and practices of special education in unconventional ways of the general education system and utilizing inclusive educational programs (Drossinou-Korea, Matousi, Panopoulos, \& Paraskevopoulou, 2016).

Many researches confirmed that the social behavior of students with ID may improve through the contact with their typical classmates. A survey that was conducted in 38 junior classes with 692 typical students and students with ID in Switzerland showed that students with ID were not particularly popular but they were socially accepted and they had friends. So, it is clear that students with ID do not require high levels of social skills to be accepted by their peers. While students with ID had lower social capabilities compared with their classmates, there was not found any serious connection between social skills and the social interaction of students with ID (Garrote, 2017). Interacting with their typical classmates in extracurricular activities had similar positive effects to children in the age of eight to 11 with ID (IQ 40-70 and $n=40$ ) (Brooks et al, 2015). In addition, Cutts and Sigafoos (2001) examined the social interactions of students with ID $(n=9)$ between peers in a junior high school in Brisbane Australia. To determine the nature and the decree of their interactions, naturalistic observations have been made. The nine students with ID in this study had a lack of social skills, but they had healthy interactions with their peers.

According to Sukhodolsky and Butter (2007), most of the definitions agree that social skills are interactions. However, a larger understanding of social skill as sufficient social function may include many other personal characteristics such as natural characteristics and expressions, language, and socio-emotional growth.

So, studies stated that simply putting students with ID in classes of general education does not automatically lead into successful social participation. Avramidis (2013) in his study examined the self-perception of students with SEN in classes of general education and their social participation into groups of their peers. This study took place in seven primary schools at north Britain. In this study, students with SEN were found to be socially lower than their classmates. The amazing thing is that students with SEN were facing their academic performances in a positive way, a fact that can be attributed to the amelioration of special educational support in normal schools, so they can meet the personalized educational goals. In what concerns their self-perception, we also had positive results. Even though they had fewer friendships and they were less popular, students with SEN felt equally accepted with their peers. The study concluded that we need to do effective educational interventions to social skills of students with or without SEN in schools of general education.

Nepi, Fioravanti, Nannini, and Peru (2015) investigated the social position of students with SEN in general classes of primary and high schools in Italy. The purpose of this study was to examine the effects of 
inclusion in different aspects of social participation, from having positive interactions between students with SEN and those without to the acceptance of the students with SEN and the growth of friendly relationships inside the group of students who grow up together as a whole. The sample consisted of 486 students between the age of seven and 14. The results showed that students with SEN like those with physical or mental disabilities are significantly less accepted. In addition, it was clear that the percentage of students with SEN is higher in high schools than that in primary schools. A fact showed that students in high schools face much more difficulties as the demands of the educational program get bigger. As a result, we had an increase in numbers of the students with SEN. Furthermore, it was found that difficulties in high school increase as the communicational situations are more demanding and the danger of rejection for the students with SEN is getting bigger.

Also, the results of a study that was conducted among 35 students with SEN and 108 students without, in general educational classes in Graz Austria, showed that children with SEN had less social participation and felt less socially integrated in their peers' groups (Schwab et al., 2015). Furthermore, students without SEN showed less indirect aggressive behavior than students with SEN while the teachers who took part in the research evaluated the positive social behavior of students without SEN better than this of the students with SEN. Researchers concluded that the poor social inclusion is not the result of the stigmatization that goes with the phrase "special educational needs", but it is a result of the students' social behaviors. So, teachers and scholars must focus in the enforcement of the social skills of students with SEN.

\section{Educational Programs of Enforcing Social Skills}

Having in mind that children with SEN have many lacks in their social skills, we need to provide them with social boosts inside school environment. O’Handley, Ford, Radley, Helbig, and Wimberly (2016) stated that the social lacks of people with ID become more obvious during high school when the expectations for social communication are bigger and the participation in the class is made through social interaction. Their research focused in the application of the program Superheroes Social Skills to ameliorate the accuracy of skills (such as expression of desires and needs, communication and waiting for my turn to speak) of adolescents with ID inside general school environment. This program included video modeling, behavioral and structured teaching interventions for the promotion of the social function and it was structured as follows:

(a) The group facilitator welcomes participants to the social skills group; (b) instruction in the target social skill and rationale for skill use is provided by animated superheroes via DVD; (c) participants engage in BST with the group facilitator, in which accurate demonstration of the target skill is modeled by the facilitator, participants engage in role-play of the target skill, and performance feedback is provided; (d) an animated social script reviewing skill steps and rationale is viewed via DVD; (e) a social game requiring use of the target skill is played; and (f) participants are provided with a reward for participation. (O’Handley et al., 2016, pp. 4-5)

Results indicated that all the participants acquired quickly the use of all the skills and with great improvement. The frequency of the worn out social function that adolescents with ID have indicates the need for effective social support with programs like "Superheroes Social Skills" which can promote effectively the acquirement, generalization, and preservation of social skills for the students with ID. The study of Plavnick, Kaid, and MacFarland (2015) in 2015 showed similar results, by utilizing an educational program of social skills in groups of students with and without ID. More specifically, they studied the application of the program "video-based group instruction" (VGI) in general high school in order to evaluate the generalization of targeted 
social skills in general school environments and also evaluate the long-term preservation of acquired social skills in students with ID. In this research participated four adolescents with autism spectrum disorders (ASD) and ID. They were asked to reach social goals, like participating in school activities together with students without SEN, etc. The aggregated results confirm that VGI can be a successful intervention model for adolescents with ASD and moderate ID. They also confirmed that this intervention can be applied in a public-school environment.

Hughes, Golas, Cosgriff, Brigham, Edwards, and Cashen (2011) mentioned that effective social skills are of great importance for the successful school performance, including participation in the classroom, academic engagement, and social interference. However, in secondary education, although conversation with teachers and peers is the main means of social interaction in the classroom and expectations for appropriate communication and the demands for social approval increase, the level of social skills in students with ID is extremely low. So, in view of limited interaction ability and very few common experiences that usually exist between classmates with or without disabilities, it is mandatory to provide education of social skills and chances for social interaction at the same time. This research studied the social skills of five students with ID, two of whom also had ASD. They were taught by their typical classmates to urge themselves using a communication book and begin speaking with other of their peers. The participants were in a general high school in southeast United States.

Communication books were composed of 3 X 4 in laminated pages, which were hole-punched and bound. On each page, a Picture Communication Symbol was printed above a typed conversational "opener" identified... as socially appropriate topics derived from a culturally diverse high school population interacting during lunchtime, such as "What class do you have next?" and "What kind of music do you like". (Hughes et al., 2011, p. 48)

In the end, it emerged that the use of communication book combined with the interaction chances made these five students more talkative with their typical classmates in school grounds. The founds of this research expand the bibliography on using communication books in students with limited social skills in many important ways and they add knowledge to the few published interventions of social skills that concern students with ID in high school.

A systematic review of 35 studies that was conducted by Garrote, Dessemontet, and Opitz (2017) to examine which interventions are effective in primary schools for the students with SEN, showed that case studies focused in teaching interaction strategies with typical classmates, group activities in academic level (cooperative learning, teaching among peers, structured game, consulting groups, etc.), as well as training of the secondary educational staff to facilitate social interactions, were found to ameliorate the social behavior of students with SEN in general educational classes. However, there is a need for more intervention studies to applicate enforcing strategies of social skills in students with SEN and especially those with learning difficulties, behavior difficulties, and mental disabilities.

In a similar way, Christakis (2011) referred to strategies that can modify the social behavior of students with ID, like the growth of cooperational skills (working in groups, homework in groups) and the use of models (modeling). The last intervention can be used with videos (video modeling) and combined with understanding of social stories. A research was conducted to look through the consequences of an intervention which used video modeling and social stories combined for people with ID to teach them social skills (Gül, 2016). The sample included three men with ID between the age of 20 and 25 . They were taught a social story through a 
video. The results showed that all the participants acquired the social skills that were set as aims with an accuracy of $100 \%$, they preserved these skills over time, and they generalized them in other cases and their social interactions.

However, teaching social skills through social stories has been implemented mainly for persons with ASD with positive effects (Chan, O'Reilly, Lang, Boutot, White, Pierce, \& Baker, 2011). The research of Choi and Nieminen (2008) proved the enforcement of positive behaviors to a student with ASD through teaching with social stories, because he could rationalize and face any problem. In this search, there were used stories that dealt with the growth of eye contact through his morning activities, his spare time activities, his participation during natural course, and how to get help. Furthermore, Chan et al. (2011) researched the evaluation of educational and teaching intervention programs by using social stories in students with ASD. They concluded that social stories can bring a little improvement to the field of the behavior and they constitute effective and easy to use means to educate kids with ASD, because they help to grow social skills and to clarify concepts that deal with knowledge of the analytical general curriculum. Finally, according to O' Connor (2009), the use of social stories as an intervention means to children with ASD is efficient. At this point, we can present some of the experiments that were conducted to prove the above. More specifically, a child with ASD that could not wait his turn for more than 30 minutes showed aggressive behavior to the rest of the group. The social story helped decrease the anger explosions of this kid.

This study focuses to teaching social skills to students with ID by using a Targeted, Individual, Structured, Integrated Program for Students with Special Educational Needs (TISIPfSENs). TISIPfSENs is trying every time to bring up the appropriate teaching methodology, the ideal models of teaching interventions, and the appropriate teaching strategies to enforce the linguistic and social skills of the students (Drossinou-Korea, 2017; Drossinou-Korea et al., 2016). The word "targeted" expresses the dynamic stance with which teachers must set functional educational goals adapted to the needs of students with ID. The educational goal for students with ID is defined by the Framework Curriculum for Special Education (FCSE) and the framework curriculum of general education, as defined by the Hellenic Pedagogical Institute and the Ministry of Education and Research and Religious Affairs respectively.

The word "individual" expresses the dynamic stance towards the individualized teaching. Personalization of the program implies the differential technique which is a basic requirement for the didactic reading methodology, mainly for students with ID (Anstonz, 2012). Gentry, Sallie, and Snaders (2013), through extensive review of the bibliography that they conducted to define the differential technique and the instrument of research (questionnaire) that was distributed to 30 undergraduate students of education, showed that the different profile of every student creates the need for the teachers to differentiate the teaching based on the theory of multi-intelligence of Howard Gardner and the physiology of the brain, which affects the readiness of the student, his interest and his mental preferences in relation with the motives, his engagement in his academic growth. According to these theories, teachers must examine his unique teaching method to orientate on how they will teach him and evaluate his needs. The differential teaching is recommended as a sail board of a teacher to succeed in the classroom and it is considered as a useful teaching strategy at schools.

The word "structured" expresses the educational principle for the need to structure the educational programs in certain phases. According to Drossinou-Korea (2017), the structure of a program contains: (1) the individual recording of the students' history by his school and family environment through experience; (2) the informal pedagogical evaluation through participatory observation (Avramidis \& Kalyva, 2006) based on the 
panels of the Basic Skills Control Lists (B.S.C.L) of special education needs that are depicted in the Framework Curriculum for Special Education (F.C.S.E.), the learning readiness, and the general learning difficulties. Participatory observation is conducted by the teacher of Special Education before the implementation of the educational program (primal observation) and after its ending (final observation); (3) the planning of the educational programd; (4) the implementation of the educational intervention; and (5) the evaluation of the educational procedure according to the recordings of the final observation and the Form of the Teaching Interaction (FTI). In that are recorded the interactional behaviors between the teacher of SE and the student, as well as the pedagogical reflection through self-observation and hetero-observation.

The word "integrated" expresses the general and specific pedagogical principle that every educational program has as a functional goal to promote the school social inclusion of the students with SEN and specifically students with ID.

\section{Purpose of the Research}

In this paper, we try to see if students with ID can acquire certain social skills through teaching by social stories. The social skills for this study, case of student refer to skills of self-sentiment (e.g., I'm happy for my success) and cooperation with others (e.g., I cooperate with my classmates), as it is defined by the board of learning readiness, to positive (e.g., I grow friendships), negative (e.g., I don't cooperate with my classmates), and delinquent behaviors (e.g., I engage in fights) as they defined by the general curriculum and autonomy skills (e.g., I take care of my personal hygiene), social behavior (e.g., I express friendly feelings), and adaptation to the environment (e.g., I know about the relations of boys and girls), as they defined by the Framework Curriculum for Special Education. It is also being searched if TISIPfSENs and its phases helped the teachers' work to plan, implement, and evaluate the educational program.

\section{Methodology}

\section{Description of Methodology Tools}

Methodology in this paper is to study a case of a student with ID who goes to a high school of Greece. In the Greek educational system, the school is divided into two levels. The first level consists of three grades and the second in three grades. The student was studying in the first level of the high school. The tools that were used are the participatory observation and Checklists of basic skills (CBS) and the Form of the Teaching Interaction (FTI) (Drossinou-Korea, 2017).

(1) Lists of control of basic skills (LCBS)

CBS of learning readiness (see Appendix: Figure 1)

The informal pedagogical evaluation of levels of learning readiness includes the neurodevelopmental skills of the speech, the psychomor ability, the mental skills, and the emotional organization.

CBS of Informal pedagogical evaluation of the levels of the special educational needs as they depict to the FCSE (see Appendix: Figure 2)

Inside the Framework Curriculum for Special Education (FCSE), the informal evaluation and completion of LCBS concerns the area of learning readiness, the basic academic skills, the social skills, the creative activities, and the pre-occupational readiness (Greek Presidential Decree: 301/1996).

CBS of Informal pedagogical evaluation (IPE) of the levels of general learning difficulties according the Greek Curriculum of Language (see Appendix: Figure 3) 
The informal pedagogical evaluation of general learning difficulties is recorded according to the framework curriculum of general education, for every class and course according to the school manuals. In general learning difficulties, the informal pedagogical evaluation and the completion of CBS concern the linguistic skills, the learning readiness skills, the math skills, and the behavioral skills.

The completion of CBS is done by excel panels as it follows: in the horizontal lines, we put the skills of every area that are evaluated according to interactive pedagogical relationship and experience for the students' performances in class and in behavior. In the vertical lines, we put the school semesters regarding the typical and mandatory education counting in ascending order from number 1 which corresponds to the first semester of attending kindergarten. A horizontal compact line that penetrates the horizontal lines is the "base line" which corresponds to the currents semester of the students according to their chronological and/or school age (In this study case of a student, the line is yellow and it was placed on the first semester of the third grade of high school). The researcher should note with an $\mathrm{x}$ the panel cell that he thinks it corresponds to the level of success for each skill. When this procedure is completed two broken lines, the first broke line (grey color) is formed that shows the disturbed or normal performance of the students in each skill during the initial observation (before to the implementation of the educational intervention) and the second broke line (red color) is formed that shows the disturbed or normal performance of the students in each skill during the final observation (after to the implementation of the educational intervention).

(2) Methodology procedure Form of the Teaching Interaction (FTI)

It is about a means of evaluating the progress and the autonomy of a student during educational intervention (Drossinou-Korea, 2017). It is visualized in a panel which includes the personal information of the student, the educational goal, the date of every educational intervention, and the recording of important crosstalk between teacher and student from the daily educational intervention. More specifically, it includes phrases of both teacher and student, as well as the commentary of their interaction that has as a goal the pedagogical reflection of the teacher and the resurgence of the educational intervention. The pedagogical reflection that is the main goal through the intervention is enforced by the self-observations and hetero-observations through the interaction with the student.

\section{Methodology Procedure}

TISIPfSENs was implemented by the following phases:

First phase of TISIPfSENs. According to the individual recording of the school and family history, the student is 18 years old and he is diagnosed with mental deficiency and immaturity and he goes to the third grade of First level of high-school of general education, when in the same time he takes educational support from a teacher of special education. The parents adopted the student nine months after his birth. In certain times, the social approach of the student in school is clumsy. At the start of the school year when he felt that other students rejected him, he was cursing, kicking, and spitting. Furthermore, it was noticed that the student expressed his sexual needs in a "special" way. He was asking from the teachers and students (male or female) to make him massages. The parents confirmed that the students expressed strongly his sexual needs by asking men and women to massage him. Massage has a sexual feeling for the student.

Second phase of TISIPfSENs: informal pedagogical evaluation. The informal pedagogical evaluation of the student was conducted through the initial participatory observation (broke line with grey color) according to three Checklists of basic skills (CBS) focusing on the students' social skill areas: 


\section{CBS of learning readiness (Figure 1)}

In "Learning readiness skills" which is mentioned in Emotional Organization, the student was evaluated in controlling his self-sentiment (like accepting his problem) 13 semesters below the base line and the cooperation with others (as to cooperate with school individuals, preserve friendly relations, etc.) 15 semesters further below the base line.

\section{CBS of special educational needs as the depict to the FCSE (Figure 2)}

In social skills, the student was evaluated in the area of Autonomy in the environment (for example to take care of his personal hygiene, etc.) five semesters of study below the base line, to adaptation to the environment skills (for example to know the relationships between boys and girls, etc.) 13 semesters of study further below the base line, and to social behavior skills (for example to express friendly feelings towards his classmates, etc.) thirteen semesters of study further below the base line.

\section{CBS of general learning difficulties (Figure 3)}

In behavioral skills, the student was evaluated in positive behaviors (for example grow social habits like friendships, etc.) 13 semesters further below the base line, in negative behaviors (for example he does not cooperate with his classmates, etc.) 13 semesters of study further below the base line, and in delinquent behavioral skills (for example engaging in fights with his classmates, etc.) 10 semesters further below the base line.

Third phase of the TISIPfSENs: a plan for structured differenced educational intervention. In the third phase of TISIPFSENS, the plan for differenced education was structured. The teacher used direct teaching, applying the educational model of task analysis. He set as an educational goal for the student to understand social stories when ameliorating his social behavior. To achieve this goal, 13 social stories were structured. Each week the student was taught a social story which he was repeatedly studying for the rest of the week.

Forth phase of the TISIPfSENs: implementation of differenced educational intervention of Social skills. In this study, we included two social stories that were structured by the teachers of SE (Special Education) and general education. For the needs of the study, the names of the students included are not real when some of the symbols-pictures included in the texts depict the student himself.

The first social story entitled "My friends" consists of 66 words and 16 pictures-symbols (see Appendix: Figure 4). The font type was Verdana. The social story was structured after the student asked his classmates (friends) to massage him. In the hetero-observations, we recorded that the reactions of the students were negative. When they heard him asking for massage, they laughed and left. Initially, we did not know where Tasos was referring when he asked for massage. When we asked him where exactly he wants to massage him, he answered at his hips. Then we understood that this word includes sexual symbolism. Furthermore, when we asked him who wants to massage him, he answered either man or woman.

The second social story had the title of "Me and Spiderman" (see Appendix: Figure 5). This social story was structured according to the students' favorite hero and his needs. The student used to spit every time his classmates ignored him. The second social story consisted of 12 pictures-symbols and 75 words.

To teach the social skills, a computer was used to adjust the font size according to the students' needs. The last one was asked to read in a slow tempo the social stories with the help of the teacher to understand the key-words of every social story that were accompanied with picture-symbols. 


\section{Results}

The results were extracted during the fifth phase of the TISIPfSENs from the participatory observation of the interactions between the student with ID and his classmates without SEN, during class and breaks after the completion of each social story. The final observation (broke line with red color) was depicted in the panels of CBS and the comments of the paper of educational interaction.

According to the final observations in the CBS panel of special educational needs as they depict to the FCSE, the student had a progress of two semesters above the initial observation in the skills "social behavior" and "adaptation in the environment"; when in "autonomy in the environment", there was not any progress. A positive overall in the profile of the student was noticed in "emotional organization", since the performance of the student was four semesters above the initial observation (Figure 1). This result is projected clearer in the panel of CBS "learning readiness", where the student in the unit of "social organization" and more particularly in "cooperating with others" had a progress of four semesters above the initial observation and in "self-sentiment" three semesters above the readings of the initial observation (Figure 2). Furthermore, in the panel of general learning difficulties, the student had an improvement of two semesters in "positive behaviors", three semesters in "negative behaviors" with the latter to be limited enough, and one semester in "delinquent behaviors" (Figure 3).

In Form of the Teaching Interaction (FTI) for these social stories, the participatory observation noticed the following: In the first social story, the student seemed to understand the information of the story with the help of picture-symbols. It was made clear to him that massage can be asked from the doctor for certain parts of his body and under certain circumstances. He stopped asking from people at school to massage him. In the second social story, the student could understand the problematic situation his behavior created by understanding the relations between boys and girls. He was given an alternative solution for the fulfillment of his needs and when he applied it, he was rewarded with his favorite song "Mary in yellows". The third social story helped improve the social relationships with his classmates and his female classmate.

\section{Conclusion}

To begin with the effectiveness of the TISIPFSENS to a student with ID in a general school derives from the initial results of the paper. Research of Drossinou et al. (2016) when testing the effectiveness of it in various school structures in three students with ASD and mild mental retardation showed that the writing, the structure, and the organization of the educational paper can change the level of these students' performance in a positive way in what concerns the social organization skills and spoken word having as a goal their school inclusion.

The teaching of social stories ameliorated the social behavior of the student. This is also confirmed from Reynhout and Carter (2007), who examined the effectiveness of the application of a social story to an eight-year-old student with ID and ASD. More specifically, the student could not join a conversation and his speech was limited from two to three words. He could follow basic instructions, but he could not satisfy his personal needs of self-preservation and he could read more than 300 image-words. After the teaching of the social story, the student decreased inappropriate and repeating knockings with his hands on the desk. The researcher concluded that the intervention of social stories that were specifically designed for children with ID and ASD seems to be appropriate also for children with medium levels of ID. 
The educational interventions that are focused on the enforcement of social skills are a basic priority for the inclusion of students with ID inside the school community. The search of Kemp and Carter (2001) in 22 students with medium ID who had received a preschool inclusive intervention and then continued in inclusive classes showed that students with ID had lower levels of social skills but they interacted with their classmates and they were accepted by them.

The future concerns for the inclusion of students with ID maybe should go further from where the students are being taught and focus to how and with what they are being taught. Sukhodolsky and Butter (2007), while examining studies about lacks of social skills in students with ID, they referred in certain studies concerning Social Skills Training (SST). Most of the SST programs are based on task analysis procedures where social duties are distributed in little steps. They include techniques of instruction, modeling, rehearsal, corrective feedback, and reinforcement skills and they focus in Interaction Skills for the enforcement of linguistic and non-linguistic skills, in social game or Use of Board Games to enforce the cooperation skills. More than that, SST is implemented with Peer Mediation as the peers affect the increase of the quality and the quantity of the interactions, the growth of friendly relationships and the higher levels of acceptance from their classmates, as well as the social problem-solving training techniques which are essential components of SST. All the above interventions suggested that they can ameliorate the social skills of kids and adolescents with ID aiming for the promotion of their school inclusion.

Through the conduct of this study and her limitations, we have the needs to determine future directions of research aiming for further improvement of the methods of teaching and approach in special treatment and education. So, it is mandatory to expand the research by using TISIPfSENs in other studies for students with ID and social difficulties, in high-school so we can have more valid results concerning the effectiveness of the social story teaching. It would be also important to pay attention to studying and improving the behavior of the students without SEN who interact with students with ID in general school.

\section{References}

Ainscow, M., Booth, T., \& Dyson, A. (2006). Improving schools, developing inclusion. London: Routledge.

Ainscow, M., Dyson, A., \& Weiner, S. (2013). From exclusion to inclusion: Ways of responding in schools to students with special educational needs. England: CfBT Education Trust. 60 Queens Road, Reading, RG1 4BS.

American Psychiatric Association. (2013). Diagnostic and statistical manual of mental disorders fifth edition (DSM V). Washigton, DC, London, England: American Psychiatric Publishing.

Anstotz, C. (2012). Fundamentals of pedagogy for children with mental retardation. In A. Zoniou-Sideri, Ed.; L. Anagnostou, Trans. Athens: Pedio, in greek.

Avissar, G., Licht, P., \& Vogel, G. (2016). Equality? Inclusion? Do they go hand-in-hand? Policy makers' perceptions of inclusion of pupils with special needs - an exploratory study. Universal Journal of Educational Research, 4(5), 973-979.

Avramidis, E. (2013). Self-concept, social position and social participation of pupils with SEN in mainstream primary schools. Research Papers in Education, 28(4), 421-442.

Avramidis, E., \& Kalyva, E. (2006). Research methods in special education. Athens: Papazisi, in greek.

Avramidis, E., \& Norwich, B. (2002). Teachers' attitudes towards integration/inclusion: A review of the literature. European Journal of Special Needs Education, 17(2), 129-147.

Bouck, E., \& Park, J. (2016). Inclusion and students with an intellectual disability. In General and special education inclusion in an age of change: Impact on students with disabilities (pp. 49-64). England: Emerald Group Publishing Limited.

Brooks, B. A., Floyd, F., Robins, D., \& Chan, W. Y. (2015). Extracurricular activities and the development of social skills in children with intellectual and specific learning disabilities. Journal of Intellectual Disability Research, 59(7), 678-687. 
Chan, O'Reilly, Lang, Boutot, White, Pierce, \& Baker. (2011). Evaluation of a social stories intervention implemented by pre-service teachers for students with autism in general education settings. Research in Autism Spectrum Disorders, 5(2), 715-721.

Choi, S. H., \& Nieminen, T. (2008). Focus on practice: Naturalistic intervention for Asperger syndrome-a case study. British Journal of Special Education, 35(2), 85-91.

Christakis, K. (2011). Behavioral problems in school age. Athens: Diadrasi, in greek.

Cornelius, D. J., \& Balakrishnan, J. (2012). Inclusive education for students with intellectual disability. Disability, CBR \& Inclusive Development, 23(2), 81-93.

Cutts, S., \& Sigafoos, J. (2001). Social competence and peer interactions of students with intellectual disability in an inclusive high school. Journal of Intellectual and Developmental Disability, 26(2), 127-141.

Drossinou-Korea, M. (2017). Special education and training. The special education proposal for children and young people with special needs. PATRA: Opportuna, in greek.

Drossinou-Korea, M., \& Panopoulos, N. (2017). Improving reading difficulties in a student with mental retardation: A case study from the Peloponnese Region. Journal of Regional Sociol-Economic Issues, 7(1), 34-48.

Drossinou-Korea, M., Matousi, D., Panopoulos, N., \& Paraskevopoulou, A. (2016). School inclusion programmes (SIPs). Journal of Research in Special Educational Needs, 16(S1), 967-971.

Garrote, A. (2017). Relationship between the social participation and social skills of pupils with an intellectual disability: A study in inclusive classrooms. Frontline Learning Research, 5(1), 1-15.

Garrote, A., Dessemontet, R., \& Opitz, E. (2017). Facilitating the social participation of pupils with special educational needs in mainstream schools: A review of school-based interventions. Educational Research Review, 20, 12-23.

Gentry, R., Sallie, A. P., \& Sanders, C. A. (2013). Differentiated instructional strategies to accommodate students with varying needs and learning styles (online submission). Retrieved from http://files.eric.ed.gov/fulltext/ED545458.pdf

Gül, S. (2016). The combined use of video modeling and social stories in teaching social skills for individuals with intellectual disability. Educational Sciences: Theory \& Practice, 16(1), 83-107.

Hughes, C., Golas, M., Cosgriff, J., Brigham, N., Edwards, C., \& Cashen, K. (2011). Effects of a social skills intervention among high school students with intellectual disabilities and autism and their general education peers. Research and Practice for Persons With Severe Disabilities, 36(1-2), 46-61.

Kemp, C., \& Carter, M. (2001). The social skills and social status of mainstreamed students with intellectual disabilities. Educational Psychology, 22(4), 391-411.

McNally, R. D., Cole, P. G., \& Waugh, R. F. (2001). Regular teachers' attitudes to the need for additional classroom support for the inclusion of students with intellectual disability. Journal of Intellectual and Developmental Disability, 26(3), 257-273.

Nepi, L., Fioravanti, J., Nannini, P., \& Peru, A. (2015). Social acceptance and the choosing of favourite classmates: A comparison between students with special educational needs and typically developing students in a context of full inclusion. British Journal of Special Education, 42(3), 319-337.

Nitzan, N., \& Roth, D. (2014). Social skill among young children with moderate to severe intellectual disability: A comparative study of parents' and teachers' reports and its correlation with parental stress. Issues in Special Education \& Inclusion, 27(1), 79-97.

O'Connor, E. (2009). The use of social story DVDs to reduce anxiety levels: A case study of a child with autism and learning disabilities. Support for Learning, 24(3), 133-136.

O’Handley, R., Ford, W., Radley, K., Helbig, K., \& Wimberly, J. (2016). Social skills training for adolescents with intellectual disabilities: A school-based evaluation. Behavior Modification, 40(4), 1-27.

Plavnick, J., Kaid, T., \& MacFarland, M. (2015). Effects of a school-based social skills training program for adolescents with autism spectrum disorder and intellectual disability. Journal of Autism and Developmental Disorders, 45(9), 2674-2690.

Reynhout, G., \& Carter, M. (2007). Social story ${ }^{\mathrm{TM}}$ efficacy with a child with autism spectrum disorder and moderate intellectual disability. Focus on Autism and Other Developmental Disabilities, 22(3), 173-181.

Schwab, S., Gebhardt, M., Krammer, M., \& Gasteiger-Klicpera, B. (2015). Linking self-rated social inclusion to social behaviour. An empirical study of students with and without special education needs in secondary schools. European Journal of Special Needs Education, 30(1), 1-14.

Soulis, S. G., Georgiou, A., Dimoula, K., \& Rapti, D. (2016). Surveying inclusion in Greece: Empirical research in 2683 primary school students. International Journal of Inclusive Education, 20(7), 770-783. 
Strogilos, V., \& Tragoulia, E. (2013). Inclusive and collaborative practices in co-taught classrooms: Roles and responsibilities for teachers and parents. Teaching and Teacher Education, 35, 81-91.

Sukhodolsky, D., \& Butter, E. (2007). Social skills training for children with intellectual disabilities. In Handbook of intellectual and developmental disabilities (pp. 601-618). US: Springer.

United Station. (2006). Convention on the rights of persons with disabilities and optional protocol. New York: United Station.

Vlachou, A. (2006). Role of special/support teachers in Greek primary school: A counterproduct effect of inclusion practices. International Journal of Inclusive Education, 10(1), 39-58.

World Health Organization. (2014). The ICD-10 international classification of mental and behavioural disorders. In Clinical

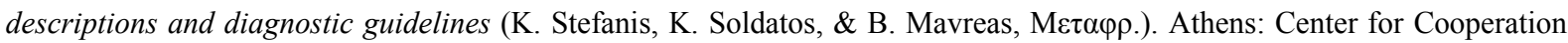
in Education and Research on Mental Health.

Appendix

Methodology of Observation

\begin{tabular}{|c|c|c|c|c|c|c|c|c|c|c|c|c|c|c|c|c|}
\hline \multicolumn{17}{|c|}{ Learning Readiness } \\
\hline & \multicolumn{7}{|c|}{ Name Students: T. } & \multirow{2}{*}{\multicolumn{6}{|c|}{$\begin{array}{l}\text { Third grade of High school - First } \\
\text { Semester } \\
\text { Mental Skills } \\
\end{array}$}} & \multirow{2}{*}{\multicolumn{3}{|c|}{\begin{tabular}{|c|} 
Age: 18 \\
Emotional Organization
\end{tabular}}} \\
\hline \multirow{2}{*}{$\begin{array}{l}\text { Grades/Semeste } \\
\text { rs }\end{array}$} & \multicolumn{3}{|c|}{ Oral Language } & \multicolumn{4}{|c|}{ Psyhomotor Activity } & & & & & & & & & \\
\hline & Hearing & $\begin{array}{r}\text { Particip } \\
\text { ation in } \\
\text { the } \\
\text { dialogu } \\
\mathrm{e}\end{array}$ & $\begin{array}{l}\text { Express } \\
\text { ion with } \\
\text { clarity }\end{array}$ & \begin{tabular}{|l|} 
Strong \\
Thin \\
mobiility
\end{tabular} & $\begin{array}{l}\text { Orienta } \\
\text { tion }\end{array}$ & \begin{tabular}{|l|} 
Rhythm \\
and \\
Time
\end{tabular} & $\begin{array}{l}\text { Lateralit } \\
\text { y }\end{array}$ & $\begin{array}{l}\text { Optical } \\
\text { memor } \\
\text { y }\end{array}$ & $\begin{array}{l}\text { Acoustic } \\
\text { memor } \\
y\end{array}$ & \begin{tabular}{|l|} 
Worker \\
memor \\
y
\end{tabular} & $\begin{array}{l}\text { Attentio } \\
n \\
\text { concent } \\
\text { ration }\end{array}$ & \begin{tabular}{|l|} 
Syllogis \\
m
\end{tabular} & \begin{tabular}{c|} 
Logical \\
mathe \\
matics \\
Think
\end{tabular} & $\begin{array}{l}\text { Self- } \\
\text { esteem }\end{array}$ & \begin{tabular}{|l|} 
Interest \\
in \\
learning
\end{tabular} & $\begin{array}{l}\text { Cooper } \\
\text { ation } \\
\text { with } \\
\text { others }\end{array}$ \\
\hline 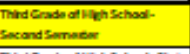 & & & & & & & & & & & & & & & & \\
\hline 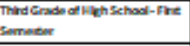 & & & & & & & & & & & & & & & & \\
\hline 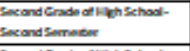 & & & & & & & & & & & & & & & & \\
\hline 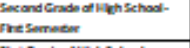 & & & & & & & & & & & & & & & & \\
\hline 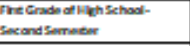 & & & & & & & & & & & & & & & & \\
\hline 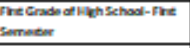 & & & & & & & & & & & & & & & & \\
\hline 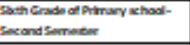 & & & & & & & & & & & & & & & & \\
\hline 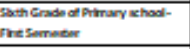 & & & & & & & & & & & & & & & & \\
\hline 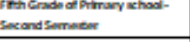 & & & & & & & & & & & & & & & & \\
\hline 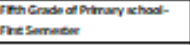 & & & & & & & & & & & & & & & & \\
\hline 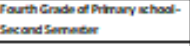 & & & & & & & & & & & & & & & $\mathrm{x}$ & \\
\hline 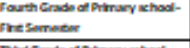 & & & & & & & & & & $x$ & $x$ & & & & & $\mathrm{x}$ \\
\hline 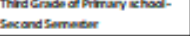 & & & & & & & & & & & & & & & & \\
\hline 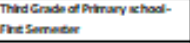 & $x$ & & & & & & & & & & & & & & & \\
\hline 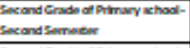 & & & & & & & $\mathrm{x}$ & & & & & & & & & \\
\hline 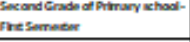 & & & & & & & $\bar{x}$ & 7 & -1 & & & $x$ & $x$ & & & $\mathrm{x}$ \\
\hline 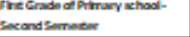 & $\dot{\mathrm{x}}$ & & & & & & & & & & & & & & & \\
\hline
\end{tabular}

Figure 1. Informal pedagogical evaluation of learning readiness with Control List of Basic Skills. 


\begin{tabular}{|c|c|c|c|c|c|c|c|c|c|c|c|c|c|c|c|}
\hline \multicolumn{16}{|c|}{ Methodology of Observation } \\
\hline Frame Curriculum $\mathrm{f}$ & or Special & 1 Educati & & & & & & & & & & & & & \\
\hline \multirow[t]{3}{*}{ Grades/Semesters } & \multicolumn{5}{|c|}{ Name Students: $T$. } & \multicolumn{6}{|c|}{ Third grade of High school - First } & \multicolumn{4}{|c|}{ Age: 18} \\
\hline & \multicolumn{4}{|c|}{ Learning Readiness } & \multicolumn{4}{|c|}{ Basic School Skills } & \multicolumn{3}{|c|}{ Social Skills } & \multicolumn{2}{|c|}{$\begin{array}{l}\text { Creative } \\
\text { Activities }\end{array}$} & \multicolumn{2}{|c|}{$\begin{array}{l}\text { Pre-Vocational } \\
\text { Readness }\end{array}$} \\
\hline & $\begin{array}{l}\text { Oral } \\
\text { Langua } \\
\text { ge }\end{array}$ & \begin{tabular}{|l|} 
Psyhom \\
otor \\
Activitie \\
5
\end{tabular} & $\begin{array}{l}\text { Mental } \\
\text { Skills }\end{array}$ & \begin{tabular}{|l|} 
Emotion \\
al \\
Organiz \\
ation
\end{tabular} & Reading & $\begin{array}{l}\text { Copreh } \\
\text { ension }\end{array}$ & Writing & $\begin{array}{l}\text { Mathe } \\
\text { matics }\end{array}$ & \begin{tabular}{|l|} 
Autono \\
my in \\
the \\
Environ \\
met
\end{tabular} & \begin{tabular}{|l|}
$\begin{array}{l}\text { Social } \\
\text { Behavio } \\
\text { r }\end{array}$ \\
\end{tabular} & \begin{tabular}{|l|} 
Adaptat \\
ion in \\
the \\
Environ \\
ment \\
\end{tabular} & $\begin{array}{l}\text { Free } \\
\text { Time } \\
\end{array}$ & $\begin{array}{l}\text { Aesthiti } \\
\text { c Arts }\end{array}$ & \begin{tabular}{|l|} 
Pre - \\
Vocatio \\
nal \\
Skills
\end{tabular} & $\begin{array}{l}\text { Vocatio } \\
\text { nal } \\
\text { Orienta } \\
\text { tion }\end{array}$ \\
\hline 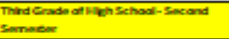 & & & & & & & & & & & & & & & \\
\hline 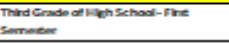 & & & & & & & & & & & & & & & \\
\hline 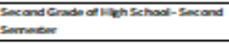 & & & & & & & & & & & & & & & \\
\hline 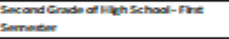 & & & & & & & & & & & & & & & \\
\hline 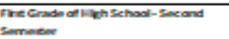 & & & & & & & & & & & & & & & \\
\hline 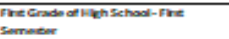 & & & & & & & & & & & & & & & \\
\hline 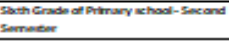 & & & & & & & & & & & & & & & \\
\hline 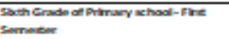 & & & & & & & & & & & & & & & \\
\hline 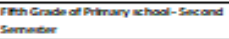 & & & & & & & & & & & & & & & \\
\hline 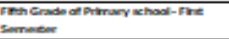 & & & & & & & & & & & & $\mathrm{x}$ & & & \\
\hline 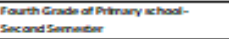 & & & & & & & & & & & & & & & \\
\hline 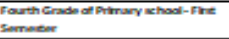 & & & & $x$ & & & & & & $x$ & $x$ & & & & \\
\hline 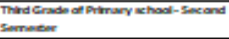 & & & $x$ & & & & & & & & & & $x$ & $x$ & te \\
\hline 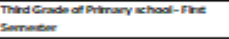 & $\bar{x}$ & $x$ & & & & & 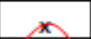 & & & 5 & $\mathbf{x}$ & & & & \\
\hline 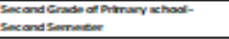 & & $\pi$ & $\mathrm{x}$ & & & & & & & & & & & & \\
\hline 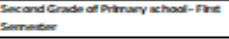 & & & & $x$ & $x$ & & & $x$ & & & & & & & \\
\hline 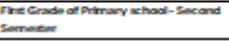 & $\mathbf{x}$ & & & & & $x$ & $x$ & 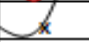 & & & & & & & $x^{3}$ \\
\hline 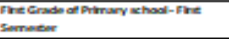 & & & & & & & & & & & & & & & \\
\hline 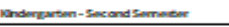 & & & & & & $\angle$ & & & & & & & & & \\
\hline 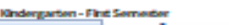 & & & & & & $x$ & & & & & & & & & \\
\hline
\end{tabular}

Figure 2. Informal pedagogical evaluation of the special educational needs according the Framework Curriculum for Special Education.

\begin{tabular}{|c|c|c|c|c|c|c|c|c|c|c|c|c|c|}
\hline \multicolumn{14}{|c|}{ Methodology of Observation } \\
\hline \multicolumn{14}{|c|}{ General Learing Disabilities } \\
\hline \multirow[t]{3}{*}{ Grades/Semesters } & \multicolumn{7}{|c|}{ Name Students: $\mathrm{T}$. } & \multirow{2}{*}{\multicolumn{3}{|c|}{$\begin{array}{l}\text { Third grade of High school - } \\
\text { First_Semester } \\
\text { Mathematics Skills }\end{array}$}} & \multirow{2}{*}{\multicolumn{3}{|c|}{\begin{tabular}{|l} 
Age: 18 \\
Behavioral Skills \\
\end{tabular}}} \\
\hline & \multicolumn{3}{|c|}{ Language Skills } & \multicolumn{4}{|c|}{ Learning Readiness Skills } & & & & & & \\
\hline & Reading & $\begin{array}{c}\text { Copre } \\
\text { hensio } \\
\mathbf{n}\end{array}$ & $\begin{array}{c}\text { Writin } \\
\text { g }\end{array}$ & $\begin{array}{c}\text { Oral } \\
\text { Langua } \\
\text { ge }\end{array}$ & $\begin{array}{c}\text { Psyho } \\
\text { motor } \\
\text { Activit } \\
\mathbf{y}\end{array}$ & $\begin{array}{l}\text { Menta } \\
\text { I Skills }\end{array}$ & $\begin{array}{c}\text { Emotio } \\
\text { nal } \\
\text { Organi } \\
\text { zation }\end{array}$ & $\begin{array}{c}\text { Numb } \\
\text { ers }\end{array}$ & \begin{tabular}{|c|} 
mathe \\
matica \\
1 \\
operat
\end{tabular} & \begin{tabular}{|c|} 
Solving \\
Mathe \\
matica \\
1
\end{tabular} & \begin{tabular}{|c|} 
Positiv \\
e \\
Behavi \\
or
\end{tabular} & \begin{tabular}{|c|} 
Negati \\
ve \\
Behavi \\
or
\end{tabular} & $\begin{array}{c}\text { Delinq } \\
\text { uent } \\
\text { Behavi } \\
\text { or }\end{array}$ \\
\hline 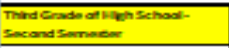 & & & & & & & & & & & & & \\
\hline 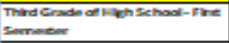 & & & & & & & & & & & & & \\
\hline 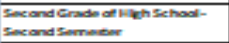 & & & & & & & & & & & & & \\
\hline 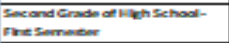 & & & & & & & & & & & & & \\
\hline 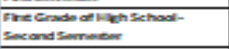 & & & & & & & & & & & & & \\
\hline 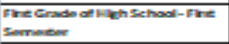 & & & & & & & & & & & & & \\
\hline 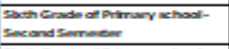 & & & & & & & & & & & & & \\
\hline 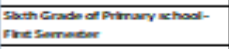 & & & & & & & & & & & & & \\
\hline 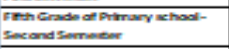 & & & & & & & & & & & & & \\
\hline 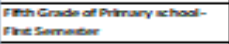 & & & & & & & & & & & & & \\
\hline 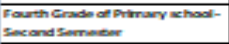 & & & & & & & & & & & & & \\
\hline 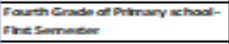 & & & & & & & & & & & & & \\
\hline 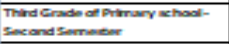 & & & & & & & & & & & & & \\
\hline 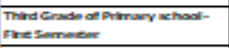 & & & & & & & & & & & & & \\
\hline 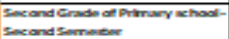 & $x$ & & & & & & & & & & & & \\
\hline 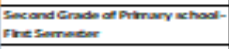 & & & & & & & & & & & & & \\
\hline 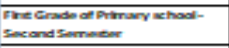 & & & & & & & & & & & & & \\
\hline 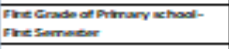 & & & & & & & & & & & & & \\
\hline 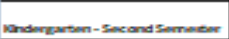 & & & & & & & & & & & & & \\
\hline
\end{tabular}

Figure 3. Informal pedagogical evaluation of general learning difficulties according the Greek Curriculum with Control List of Basic Language Skills. 
My friends

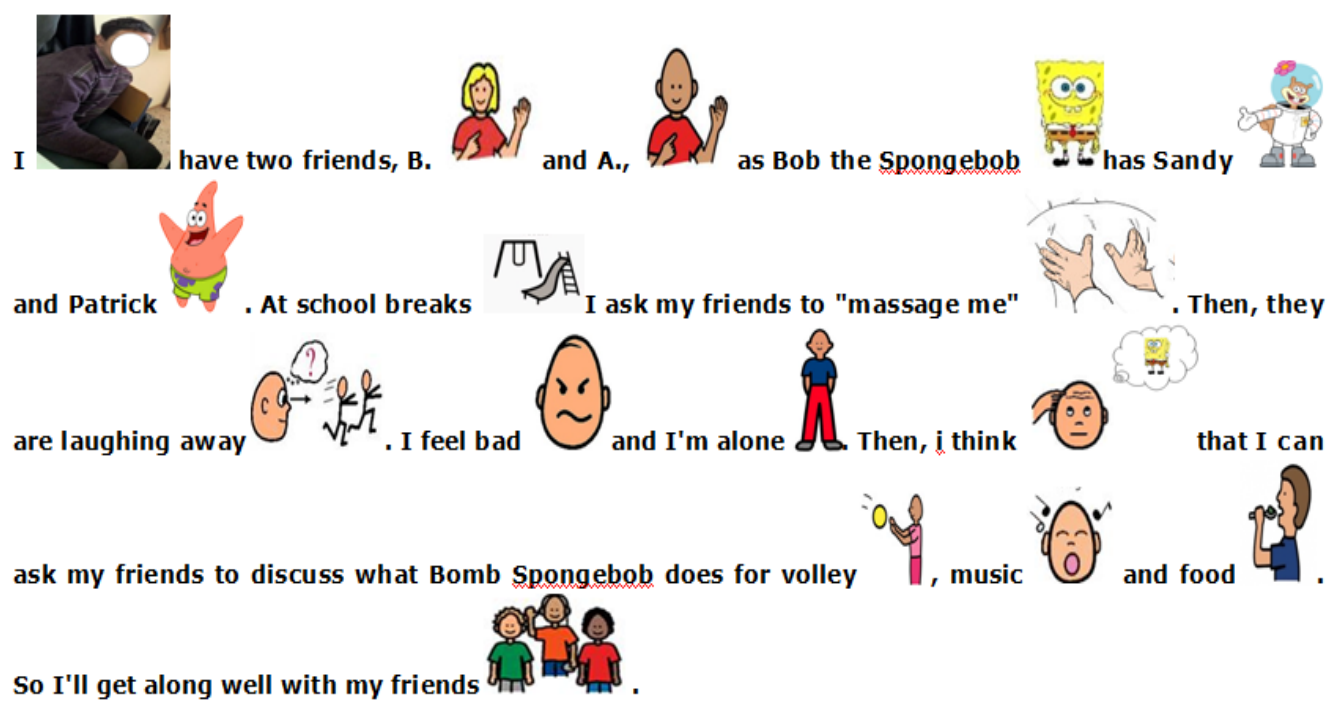

Figure 4. Social story "My Friends".

Me and Spiderman
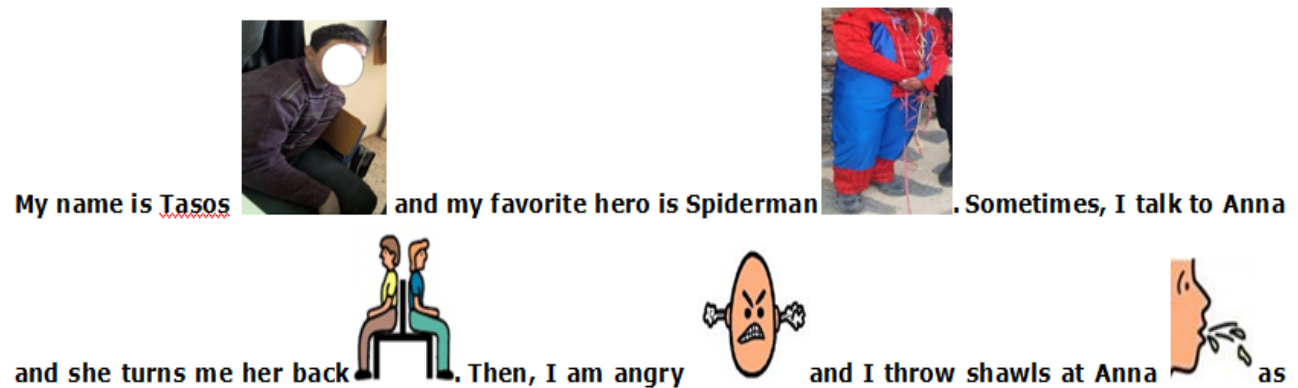

and she turns me her back and I throw shawls at Anna as
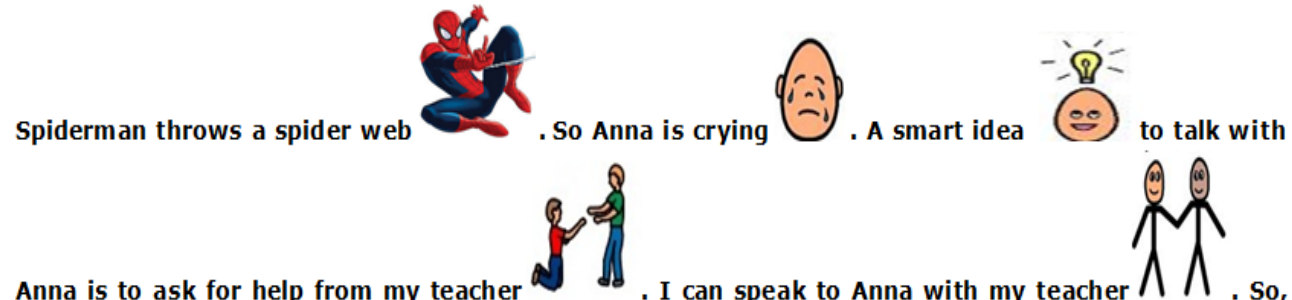

Anna is happy

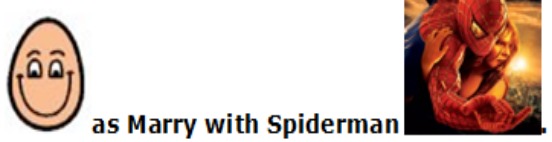

Figure 5. Social story "Me and Spiderman". 